


\section{ISO Environmental Management Standardization Efforts}

Mary H. Saunders

U.S. DEPARTMENT OF COMMERCE Technology Administration National Institute of Standards and Technology

Gaithersburg, MD 20899

February 1996

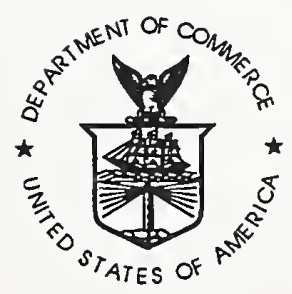

U.S. DEPARTMENT OF COMMERCE Ronald H. Brown, Secretary

TECHNOLOGY ADMINISTRATION Mary L. Good, Under Secretary for Technology

NATIONAL INSTITUTE OF STANDARDS

AND TECHNOLOGY

Arati Prabhakar, Director 


\section{Table of Contents}

\section{ABSTRACT}

Introduction

Europe's Eco-management and Audit Scheme - Role of

International Standards . . . . . . . . . . . . . 2

Management Standards in the International Organization for

Standardization . . . . . . . . . . . . . . 3

More on Occupational Health and Safety Management Standards . 4

Environmental Management Systems . . . . . . . . . . 5

Environmental Auditing . . . . . . . . . . . . . 6

Environmental Labelling . . . . . . . . . . . . . 6

Environmental Performance Evaluation . . . . . . . . . 7

Life Cycle Assessment . . . . . . . . . . . . . . . 8

Environmental Aspects of Product Standards . . . . . . . . . 8

The Role of Third Party Certification . . . . . . . . . . 9

Summary and Conclusions . . . . . . . . . . . . . . . . 11

Annex I . . . . . . . . . . . . . . . . . . 13

Annex II . . . . . . . . . . . . . . . . 15

Annex III . . . . . . . . . . . . . . . . . 17 


\section{ABSTRACT}

The International Organization for Standardization (ISO) is currently developing a family of "environmental management" standards which address management systems and the environmental aspects of products in the areas of life cycle assessment and labelling. These standards have the potential to exert a significant influence on the design, manufacture and marketing of products. They are also likely to affect the type of environmental data gathered by businesses and how those data are communicated internally and externally. This report outlines the current state of development of these planned ISO standards and also covers developments relating to third party certification of environmental management systems.

KEY WORDS: environment, environmental management, environmental labelling, life cycle assessment 


\section{ISO ENVIRONMENTAL MANAGEMENT \\ STANDARDIZATION EFFORTS}

\section{Introduction}

The International Organization for standardization (ISO) is currently developing a family of "environmental management" standards which address management systems and the environmental aspects of products in the areas of life cycle assessment and labelling. These standards have the potential to exert a significant influence on the design, manufacture and marketing of products. They are also likely to affect the type of environmental data gathered by businesses and how those data are communicated internally and externally. Work on internationallyagreed standards in the life cycle and labelling areas is not expected to be completed until 1997 or 1998. Environmental management system standards and related auditing standards will be issued as final international standards by mid-1996.

Iso Technical Committee (TC) 207 on Environmental Management standardization was formed in June 1993, following the recommendation of a Strategic Advisory Group on the Environment (SAGE) which ISO convened in 1991 to determine whether there was a need to undertake standards development in this area. The Canadian Standards Association (CSA) administers the secretariat for TC 207, on behalf of the Standards Council of Canada (SCC), Canada's ISO member body. The scope of TC 207 is "standardization in the field of environmental management tools and systems." It excludes test methods for pollutants, setting limit values regarding pollutants or effluents, setting environmental performance levels, and standardization of products. However, through its working group on environmental aspects of product standards, TC 207 is providing guidance to product-specific TC's for evaluating environmental effects of products and services, and the effect business operations have on the environment. Individual standards approved by TC 207 and adopted by ISO as international standards will be designated as part of the ISO 14000 series.

TC 207 oversees six subcommittees and one working group (see Annex I), which together have a total of some 25 work items under consideration. In general, TC 207 subcommittees dealing with environmental management systems, environmental auditing and environmental performance evaluation are focusing on process management (how) as opposed to outcomes (what). The subcommittees responsible for generating standards for life cycle assessment and labelling are seeking to establish principles and uniform approaches to product evaluation and communication of environmental attributes. 
Forty-seven Iso member bodies participate in the work of the TC 207, and another 15 have observer status. European countries represent the largest geographical grouping participating in technical committee. Iso has also recognized 22 international or regional non-governmental liaison groups interested in sharing information with TC 207. These include international environmental organizations, industry associations and other entities.

The ISO member body for the United States, the American National Standards Institute, has designated ASTM (formerly known as the American Society for Testing and Materials) to manage U.S. participation in TC 207. ASTM also serves as the U.S. Technical Advisory Group (TAG) administrator for three TC 207 subcommittees--environmental performance evaluation, life cycle assessment, and terms and definitions. The American society for Quality Control (ASQC) is the TAG administrator for two subcommittees--environmental management systems and auditing. NSF International has recently taken over administration of U.S. TAG activities relating to the subcommittee responsible for environmental labelling standards. (See Annex II for contact information) The United States also provides the secretariat for subcommittee four, on environmental performance evaluation.

\section{Europe's Eco-management and Audit Scheme - Role of International Standards}

European influence is evident in the pressure being exerted on TC 207 to develop environmental management system (EMS) and auditing standards quickly, so that international standards are available to support new European legislation regarding an Eco-audit and Management Scheme (EMAS), which went into effect in April 1995. EMAS is a voluntary system which allows European Union (EU) member state governments to recognize organizations operating manufacturing facilities in Europe that meet a relatively detailed EMS and auditing protocol.

In 1994, the European Commission issued a draft mandate to the regional standards setting body, Comite Europeen de Normalisation (CEN), to produce regional standards to support this legislation. In November 1994, a special CEN working group determined that, in general, TC 207's EMS specification and auditing standards would meet the technical requirements of EMAS. CEN recommended to the European Commission that regional standards work be deferred in favor of the ISO standards, provided these standards could be finalized as soon as possible. To meet demand from Europe, TC 207 members agreed to a rapid timetable to develop and approve the four standards deemed critical to EMAS implementation approximately 30 months. CEN representatives were directly involved in development of these documents. As a result, four of the six draft international standards (DIS's) currently out for 
ballot by TC 207 are also being voted on in parallel by CEN members for acceptance as European regional standards.

There are several differences remaining between EMAS and ISO's draft EMS specification and auditing standards in the 14000 series. For example, EMAS requires an extensive environmental review as part of the EMS. This is not specifically required in ISO 14001. EMAS also requires a participating company to publish a validated public environmental statement and to make publicly available its policies, programs and EMS system. ISO 14001 requires only that the environmental policy be made available to the public. EMS requirements in EMAS call for the preparation of an environmental effects register, which is not required in Iso 14001. EMAS appears to call for more extensive auditing activities than does ISO 14001, and specifies a maximum audit frequency of three years. EMAS also focuses more directly on improvement of environmental performance than does ISO 14001 . The draft standard places more emphasis on establishing and improving the system itself; improvement in environmental performance is implied but not explicitly referenced.

CEN plans to develop a report comparing the Council Regulation establishing EMAS and ISO DIS 14001, 14010, 14011, and 14012. CEN has also established an EMAS working group to draft a "bridging document" describing the requirements that sites in the European Union would have to meet in addition to those in Iso 14001 to bridge the differences between the two. Finally, CEN recently decided to reassess the need to develop a European standard on the "environmental statement" before the end of 1996.

\section{Management standards in the International Organization for Standardization}

Its work in the area of environmental management standards is ISO's second foray into the development of management standards. The ISO 9000 series of standards, first issued in 1987 and revised in 1994, describes the elements necessary for organizations to establish and maintain quality management systems. ISO has also released ISO 10011, which establishes basic auditing principles as well as general guidelines for establishing, planning, implementing and documenting audits of quality systems.

During the two years preceding ISO's creation of TC 207, participants in ISO's Strategic Advisory Group on the Environment (SAGE) debated the relationship between the ISO 9000 series of standards developed by TC 176 and the planned work of TC 207 . There are issues common to both quality management systems and environmental management systems, which would also be common to standards describing such systems. Some examples are operational control, audits, communication, training and corrective action. 
However, SAGE felt that while the two standardization areas share some basic principles, the knowledge required for environmental management and environmental auditing is quite different from quality management and auditing. SAGE members therefore determined that a separate technical committee should be created to develop environmental management standards, and that this committee should involve disciplines that were unavailable in $\mathrm{TC}$ 176. It was agreed that the two committees would coordinate their work to ensure the compatibility of standards in both areas.

In order to facilitate this coordination, Iso established a formal liaison between TC 207 and TC 176. Klaus Petrick, leader of the German delegation to TC 176, heads this delegation. Liaison group members determined that harmonization between TC 176 and TC 207 in their approach and documentation was critical to minimize the burden of the evolving environmental management standards on industry and to avoid the creation of non-tariff barriers. Compatibility will also facilitate efforts of organizations wishing to establish a single, integrated management system covering all of their activities. This coordination was considered to be most important in the areas of EMS and auditing standards (TC 207 subcommittees 1 and 2). Coordination has been formally agreed to within TC 207 at the subcommittee level, although subcommittee members also specified that their work should not be bound to line-by-line consistency with standards developed by TC 176.

More recently, the ISO Technical Management Board (TMB) has been asked to consider the development of standards in the occupational health and safety management area. Several countries already have such standards, including Norway, the United Kingdom and Australia. The TMB has determined that the development of international occupational health and safety standards raises several controversial issues. Iso has decided to convene an international conference on the topic in the fall of 1996, before deciding whether to proceed to develop standards in this area.

\section{More on Occupational Health and Safety Management standards}

In the United States, the American Industrial Hygiene Association (AIHA) has announced its intention to develop guidelines to assist companies in implementing an occupational health and safety (OH\&S) management system. The proposed guidelines would track the language and concepts found in the ISO $14000 \mathrm{EMS}$ standards. AIHA plans to publish a document by the end of 1996 for its membership and partnering organizations, in anticipation of a decision by ISO on whether or not to initiate development of an international standard for OH\&S management. 
No firm position has yet been established within the U.S. private sector on support for either national or international standards for OH\&S management. ANSI will sponsor a U.S. workshop to develop a national position on the desirability of developing international OH\&S management standards in May 1996, in preparation for an ISO conference on this topic currently scheduled for september 1996. The IsO conference will attempt to identify stakeholders and their needs, to begin an assessment of the value of OH\&S management standards, and to outline differences in perception between countries with high and low levels of OH\&S regulation. The conference will examine existing national and regional examples of OH\&S management standards, and will also address the relationship between OH\&S management standards and other ISO management standards and guides.

\section{Environmental Management Systems}

In July 1995 TC 207 Subcommittee 1 completed work on two draft international standards (DIS), a specification standard and a general guide to environmental management principles, systems and supporting techniques. These documents are intended to provide organizations with the elements of an effective environmental management system (EMS) which can be integrated with other management requirements. The planned specification standard, Iso 14001, defines the core elements of a environmental management system. The purpose of such a system is to enable an organization "to establish and assess the effectiveness of procedures to set an environmental policy and objectives, achieve conformance with them, and demonstrate such conformance to others." 1 The standard is written to be applicable to all types and sizes of organizations and to accommodate diverse geographical, cultural and social conditions.

Some 15 countries have already produced draft EMS standards at the national level. Many are modelled after the British standard, BS 7750, first published in 1992. Both BS 7750 and the European EMAS legislation set out comparatively detailed programs for compliance and include requirements for some type of public disclosure or "environmental reporting." Many participants in the ISO process have expressed their concern that these documents are not flexible enough for global application to businesses of different types and sizes. The specification document emerging from SCl of TC 207 takes these concerns into account. While the international document encompasses the general elements of BS 7750, it allows greater flexibility in application. The European demand that the Iso standard be consistent with EMAS is addressed in an "informative annex" that will accompany the EMS specification standard. The annex addresses collateral matters

${ }^{1}$ ISO/DIS 14001: Environmental Management Systems Specification with Guidance for Use, Introduction 
such as relationships with subcontractors; the level of detail required to determine the environmental aspects of operations, products and services; and the level of detail of documentation.

Both the EMS specification and guidelines documents are currently being circulated to ISO member bodies as DIS's for vote. The six month voting period closes in mid-February 1996. Any comments received will be reconciled by SC 1 leadership. If the vote by Iso members is positive, the revised specification document (ISO 1400I) will then be circulated to CEN member bodies for a twomonth period for a second vote to adopt it as a regional standard. No changes to the document are permitted during this second voting period. Under CEN procedures, if ISO 14001 is adopted as a regional standard, all CEN members must withdraw their national environmental management system standards (e.g., BS 7750).

\section{Environmental Auditing}

TC 207 Subcommittee 2 has three documents currently out for vote as DIS's: general principles of auditing, procedures for auditing environmental management systems, and qualification criteria for environmental auditors. All three documents will be submitted to the ISO/CEN parallel voting procedure discussed above. Current plans are to issue these documents as guidelines, rather than specifications for which independent certification can be obtained. However, it has been agreed that the auditor qualifications document is applicable for use in the accreditation of environmental auditors. The standards are to be used by management as tools in the implementation of an EMS. They are baseline documents, identifying minimum criteria. The auditor qualification standard is intended to apply to all types of auditors, and does not specifically address how an auditor would audit an EMS.

Other work items under consideration by subcommittee 2 include documents on initial reviews, site assessment, and management of EMS audit programs. Work on these items has been put on hold until the 1996 plenary meeting of TC 207, pending further justification. Subcommittee members will vote in June 1996 whether to continue work in any of these areas, based on refinement of the scope and proposed work plans for these items. Work items dealing with standards for compliance auditing and environmental statement auditing have been dropped.

\section{Environmental Labelling}

TC 207 Subcommittee 3 is considering documents on several types of environmental labelling. The first document (ISO 14024) addresses multiple criteria-based practitioner programs (Type I). These are certification programs, operated either by governments or by private organizations, that communicate a judgment through 
the use of a single label that a product is "environmentally preferable" within a given product sector, based on an analysis of the product's environmental attributes. The document is intended to serve as a guide for the operation of programs such as Germany's Blue Angel, Japan's EcoMark, and the United States' Green Seal (the German and Japanese programs are governmentsponsored, while Green seal is a privately-operated program). It lays out principles and practices to use when awarding labels to products. Important elements include credibility, consultation with stakeholders, transparency, accessibility and avoiding the creation of unnecessary obstacles to international trade. In March 1995, this document was circulated as a committee draft (CD). Comments were considered at the November 1995 meeting of SC 2 in Seoul, Korea and a revised CD for comment is currently being prepared. This document is not likely to move to the DIS stage until late 1996.

Type II programs deal with self-declarations by manufacturers regarding specific aspects of a product (recyclability, energy use, etc.) and cover any self-declared environmental claims, not just labelling. The document covering these types of programs, which has emerged from the subcommittee and is currently a CD for ballot and comment, is compatible with U.S. Federal Trade Commission guidelines on the use of environmental marketing claims. Further work on this document has been postponed until progress is made on companion documents dealing with symbols, testing, and verification methodologies. The symbols document (ISO 14022) currently covers only the use of the mobius loop symbol (chasing arrows) as a general representation of the recyclability or recycled content of products, but may be extended to cover symbols specific to types of products (plastic, aluminum, etc.).

A third document under development within subcommittee 3 describes goals and principles for all types of labelling (Iso 14020). There is still substantial disagreement within SC 3 as to whether this document should be a guide or a standard. A decision on the status of the document will be taken at the June 1996 TC 207 plenary. Still under discussion within subcommittee 3 is whether the content of ISO documents should be limited to principles and methodologies to improve the art of environmental labelling, or whether they should also establish environmental improvement as the end goal of environmental labelling.

SC 3 initially committed to develop a standard for Type III programs as well; these programs cover labels that list the environmental effects associated with a particular product. Since there were few programs of this type in existence, a decision was made at the 1994 TC 207 plenary in Australia not to undertake any work in this area. However, this decision was rescinded in November 1995, on the basis that more programs exist to define work at the international level in this area. Work on 
a document addressing Type III labelling has been tentatively designated NP 14025, with Sweden as task leader.

\section{Environmental Performance Evaluation}

The goal of TC 207 Subcommittee 4 is to develop objective tools to measure, analyze, assess and describe an organization's environmental performance against specified criteria.

Environmental performance evaluation (EPE) is intended to provide guidance on performance evaluation as a distinct function within an EMS, and thus is closely related to the work of subcommittee 1. U.S. participants view EPE primarily as an internal. management tool, with the ISO standard establishing the criteria and methodology by which organizations can set their own objectives. So far, this view has prevailed, although some IsO participants want EPE to be a public measuring tool. The timetable for developing the first EPE standards extends well into 1998. There are no existing standards in this area on which to build. To date, the subcommittee has approved a framework document that provides guidance for the balance of its work. Work on performance indicators and associated evaluation methodologies covering environmental management systems, operational systems and the environment is still very preliminary.

\section{Life Cycle Assessment}

The scope of TC $207^{\prime} \mathrm{s}$ Subcommittee 5 is standardization in the field of life-cycle assessment as a tool for environmental management of product and service systems. It encompasses the assessment of the environmental impacts from the extraction of raw materials to the final disposal of waste. The subcommittee is working on documents in four areas: general principles and framework; inventory analysis; impact assessment; and interpretation. Documents on general principles and inventory analysis are the most advanced, perhaps because conceptual work has already been done in these areas by groups such as the Society of Environmental Toxicology and Chemistry (SETAC). Defining criteria and methodologies for impact assessment and interpretation is more difficult. Many subcommittee participants argue that the state of science in these areas is not sufficiently advanced to permit the development of acceptable standards.

Work in Subcommittee 5 is closely related to the work of other TC 207 subcommittees. Life cycle assessment (LCA) standards are intended to be used within a full-fledged environmental management system. Labelling programs in general are supposed to be based on life cycle concepts; and inventory analysis and impact assessments are intrinsic to an organization's evaluation of its environmental performance. Work on the general principles document is at the committee draft stage. This document 
addresses a wide range of issues, including appropriate uses of LCA, goals, types of LCA, data quality, level of detail required, and if (or when) critical review of LCAs will be required.

\section{Environmental Aspects of Product Standards}

TC 207 formed a separate working group under the leadership of Germany to develop a guidance document for use by standards writers on the environmental aspects of product standards. The stated purposes of this guidance document are to:

- raise awareness that provisions of product standards can affect the environment in both a negative and positive way;

- outline the relationship between product standards and the environment;

- help avoid provisions in product standards that may lead to adverse environmental effects;

- emphasize that addressing environmental aspects in product standards is a complex process that requires balancing competing priorities; and

- recommend the use of life-cycle thinking and recognized scientific methodologies in developing product standards that incorporate environmental aspects.

The document has reached the committee draft stage and was circulated for comment prior to the 1995 plenary of TC 207. At this meeting, TC 207 members voted to offer the document to ISO Central secretariat as a draft ISO guide by the end of 1995 . The International Electrotechnical Commission (IEC) has issued its own guidance document on environmental aspects of product standards as well. The IEC guidance is written specifically for standards writers dealing with electrical and electronic aspects of products.

\section{The Role of Third Party Certification}

TC 207's work on environmental management system standards is applicable both to self-declaration of conformance by an organization and to third party certification. Similarly, emerging auditing standards are applicable both to internal and external auditors, as well as to auditors in the employ of registrars. However, participants in TC 207 recognize that an organization may seek third party "certification" or "registration" of its management system to meet a regulatory requirement or a demand from customers and/or stakeholders for independent verification. More than a half dozen countries have or are developing accreditation programs for environmental 
certification bodies or registrars. Some are also making plans to establish programs to certify auditors and/or approve training courses. EMS registrar accreditation programs either already exist or are being established at the national level in Europe, Latin America and the Pacific Rim.

In the European Union (EU), the Council Regulation establishing the EMAS requires each member state government to "establish a system for the accreditation of independent environmental verifiers and for the supervision of their activities." Companies that wish to participate in EMAS must have their environmental policy, program, management system, review/audit procedure and environmental statement examined by an independent verifier for compliance with relevant requirements of the regulation. A company's environmental statement must also be validated by the verifier in accordance with EMAs procedures.

Iso's Council Committee on Conformity Assessment (CASCO), in conjunction with TC 207, held a workshop on environmental management and conformity assessment on June 12-13, 1995 in Geneva, Switzerland. CASCO was established by ISO to address conformity assessment issues related to ISO technical standards. Conformity assessment guides produced under the auspices of CASCO have been adopted by both ISO and IEC, and are used extensively around the world. There are CASCO guides in existence that deal with laboratory operations, product certification and quality system registration. Topics under consideration in the June workshop included conformity assessment for environmental management systems (EMS), conformity assessment for products (labelling, life cycle assessment), concerns of small and medium sized businesses and of developing countries, and the current and potential role of $\mathrm{CASCO}$ in the environmental management area. Workshop participants agreed to establish liaison between TC 207 and CASCO on matters of common interest. CASCO' leadership agreed to initiate of a review of past CASCO work in product certification and the use of marks, in light of potential developments in the environmental management arena with respect to environmental management certification logos, product certification marks and eco-labels.

EMS accreditation programs are following a variety of models. Existing programs in the United Kingdom and the Netherlands are operated by national accreditation bodies responsible for accreditation of a broad range of entities (UKAS and RVA respectively) - registrars, product certifiers and laboratories. These bodies currently accredit registrars to register companies to the British national standard, BS 7750 , although these programs will be updated when ISO 14001 is approved as an International standard. There is no provision in these programs currently for certification of auditors or accreditation of training course providers. The Swiss National Accreditation Body (SAS) is currently accrediting registrars to register companies 
to DIS/ISO 14001, the DIS having been adopted as the Swiss national standard. A similar situation exists in Austria. In Japan, the Japanese Accreditation Board (JAB), which currently accredits registrars in the ISO 9000 area, plans to extend its program to cover ISO 14001. In the United States, the American National Standards Institute, the Registrar Accreditation Board $(R A B)$, the Environmental Auditing Roundtable, the Independent Association of Accredited Registrars, as well as individual companies, are all participating in the establishment of a U.S. system which will cover registrar accreditation, auditor certification and accreditation of training course providers. The American National Standards Institute (ANSI) has begun the process of establishing a program which will cover all three areas. RAB has announced its own plans to offer registrar accreditation services.

\section{Summary and Conclusions}

The work that has been undertaken by ISO Technical Committee 207 is a critical first step in the international harmonization of environmental management programs and practices. There are clear benefits to this harmonization, both for private sector interests and for governments. Where third party certification is demanded by the market, harmonization of accreditation and certification practices can form the basis for mutual recognition of certificates. This reduces the need for businesses to obtain multiple certifications of their systems or products, and therefore reduces costs. More importantly, environmental management standards are useful for organizations seeking to improve their environmental performance. ISO 14001, the management system specification standard, calls for continual improvement of the management system. When complete, work on life cycle assessment and environmental performance evaluation standards will provide organizations with tools to assist them in establishing and improving their management systems.

Organizations that have an effective management system in place, and are committed to continual improvement of that system, should be better able to identify, track and control their environmental aspects. This is beneficial both for the organizations themselves and for their surrounding environment. It also has the potential to lead to a reduction in the burden on governments to enforce compliance with environmental regulations. While the full market impact of international environmental management standards is not likely to be determined for several years, worldwide interest and participation in the work of ISO TC 207 is a clear indicator of the importance that a broad range of stakeholders attach to this area. 
Annex I

\section{ISO/TC 207 INFORMATION}

ISO/TC 207 on Environmental Management

secretariat Canada (Canadian Standards

Association for standards Council of Canada)

scope: develop standards and guidance for the

selection and use of tools and systems (see below)

U.S. TAG Administrator: AS'TM

WG 1 Environmental Aspects in Product Standards

convener Germany

scope: develop guidance for use by other technical committees for including environmental elements in existing or forthcoming product standards

SC 1 Environmental Management Systems secretariat United Kingdom

scope: establish standards for activities to set environmental policy, objectives, and responsibilities and to implement them through planning, measures of effectiveness, and control of environmental impact

U.S. SUBTAG: ASQC

2 WGs - general guidelines (Canada and USA); specifications and general guidance on them

(France and U.K.)

SC 2 Environmental Auditing secretariat Netherlands

scope: establish standards for measuring organizational compliance with an environmental management system and for establishing the policies, directives and goals expressed by organizational policy

U.S. SUBTAG: ASQC

SC 3 Environmental Labelling secretariat Australia

scope: develop standard terminology, definitions, symbols, test methods, test summary reporting standards, etc.

U.S. SUBTAG: NSF International

SC 4 Environmental Performance Evaluation secretariat United states scope: guidance for evaluating environmental effects of products and services, and the effect business operations have on the environment U.S. SUBTAG: ASTM 
2 WGs - general principles (USA); industryspecific indicators (Norway)

SC 5 Life Cycle Analysis

secretariat France

scope: standardize programs for analyzing environmental impacts of products, processes and services during their life cycle, including the production and utilization of raw materials, manufacturing processes, distribution methods and options related to disposal or recycling

U.S. SUBTAG: ASTM

4 WGs - code of practice (USA); inventory (Japan and Germany); impact analysis (Sweden); evaluation and improvement analysis (France)

SC 6 Terms and Definitions secretariat Norway

scope: standardize terminology and coordinate the use of standards with other committees within Iso U.S. SUBTAG: ASTM

Contacts regarding U.S. participation, delegation membership:

Rose Tomasello

American Society for Testing and Materials

100 Barr Harbor Drive

West Conshohocken, PA 19428-2959

tel: 610-832-9500 fax: 610-832-9555

e-mail: service@local.astm.org

Patricia Kopp

American Society for Quality Control

$611 \mathrm{E}$. Wisconsin Avenue

Milwaukee, WI 53201-3005

tel: 414-272-8575 fax: 414-272-1734

NIST contact:

Mary Saunders

Office of Standards Services

National Institute of Standards and Technology

Gaithersburg, MD 20899

tel: 301-975-2396 fax: 301-963-2871

e-mail: mary.saunders@nist.gov 


\section{Annex II}

\section{PROPOSED ISO NUMBERING/PLANNED STANDARDS}

SC 1 - Environmental Management System

ISO 14004 general guidelines on principles, systems and supporting techniques
for ballot,

14001 August 95)

specification with guidance for use (issued as DIS for ballot, August 95)

SC 2 - Environmental Auditing and Related Environmental Investigations

ISO 14010 general principles (issued as DIS for ballot, August 95)

14011/1 environmental management system auditing

(issued as DIS for ballot, August 95)

14012

qualification criteria for environmental

ballot; auditors (issued as DIS for August 95)

Proposed new work items:

ISO 14013 management of environmental audit programs (deferred pending further justification to confirm as work item, no later than March 96)

14014 initial reviews (deferred pending further justification to confirm as work item, no later than March 96)

14015

environmental site assessment-DEFERRED AT 6/95 TC 207 MTG (further justification to confirm as work item requested no later than March 1996)

SC 3 - Environmental Labelling

ISO 14020

goals and principles of all environmental labelling ( $C D$ for comment by December 95)

14021 self-declaration environmental claims (CD for ballot and comment issued fall 1995)

14022 environmental labelling - symbols (work begun in March 1995)

14023 testing and verification methodologies for application in environmental labeling (still at working draft stage)

14024 guiding principles, practices and criteria for multiple criteria-based practitioner programs (Type I) (CD comments reviewed November 1995; revised $C D$ for ballot/comment available) 
Proposed new work items:

14025

Single criteria programs (Type III) Sweden is task leader for this item, under WG 1

SC 4 - Environmental Performance Evaluation

14031 evaluation of environmental performance (still at working draft stage)

SC 5 - Life Cycle Assessment

14040 principles and guidelines (CD out for ballot/ comment)

14041 inventory analysis (CD for comment)

14042 impact assessment (working draft under development)

14043 interpretation (NB: this was formerly titled "improvement assessment." The scope of work was modified at 1995 TC 207 plenary to focus on interpretation)

SC 6 - terms and definitions

14050 environmental management - vocabulary (working draft stage)

Working Group

14060 guide for the inclusion of environmental aspects in standards (advanced to stage of draft ISO Guide) 
Annex III

US TAG to ISO TC 207-CONTACTS

Joe Cascio, U.S.TAG Chairman

IBM

Somers, NY

tel: $914-766-2734$

fax: $914-766-2824$

Mary McKiel

EPA Coordinator for ISO 14000

U.S. TAG Vice Chair

U.S. EPA

Washington, D.C. 20460

tel: $202-260-3584$

fax: $202-260-0178$

SC1 - Environmental Management Systems

Joel Charm, Chairman

Allied Signal, Inc.

Morristown, NJ

tel: 201-455-4057

fax: $201-455-4835$

SC2 - Environmental Auditing

Cornelius (Bud) Smith, Chairman

ML Strategies, Inc.

Danbury, CT

tel: $203-778-6114$

fax: $203-778-6487$

working groups cover: auditing principles, auditing procedures, auditor qualifications

SC3 - Environmental Labelling

Jim Connaughton

Sidley and Austin

1722 Eye Street, N.W.

Washington, D.C. 20006

tel: $202-736-8364$

fax: $202-736-8711$

working groups cover: guiding principles for practitioner programs, self-declaration claims, guiding principles for environmental labelling programs 
SC4 - Environmental Performance Evaluation

John Master

c/O ARCO Chemical Company

Newton Square, PA 19073

tel: $610-359-4810$

fax: $610-359-4862$

SC5 - Life Cycle Assessment

James Fava

Roy F. Weston. Inc.

West Chester, PA 19380

tel: $610-701-3636$

fax: $610-701-7455$

SC6 - Terms and Definitions

Christopher Bell

Sidley and Austin

1722 Eye Street, N.W.

Washington, D.C. 20006

tel: $202-736-8118$

fax: 202-736-8711

WG - Environmental Aspects in Product Standards

Donald R. Theissen

3M Corporation

St. Paul, MN

tel: $612-733-6050$

fax: $612-736-9278$ 

1

1 1 